\title{
3D printed composite model of pelvic osteochondroma and nerve roots
}

\author{
Olivia Fox ${ }^{1}$ (D) and Andrew Kanawati ${ }^{1,2^{*}}$
}

\begin{abstract}
Background: 3D-printing has become increasingly utilized in the preoperative planning of clinical orthopaedics. Surgical treatment of bone tumours within the pelvis is challenging due to the complex 3D bone structure geometry, as well as the proximity of vital structures. We present a unique case where a composite bone and nerve model of the lower lumbar spine, pelvis and accompanying nerve roots was created using 3D-printing. The 3Dprinted model created an accurate reconstruction of the pelvic tumour and traversing nerves for preoperative planning and allowed for efficient and safe surgery.

Case presentation: We present a unique case where a composite bone and nerve model of the lower lumbar spine, pelvis and accompanying nerve roots was created using 3D-printing. The bony pelvis and spine model was created using the $C T$, whereas the nerve roots were derived from the MRI and printed in an elastic material. 3Dprinted model created an accurate reconstruction of the pelvic tumour and traversing nerves for preoperative planning and allowed for efficient and safe surgery. Pelvic tumour surgery is inherently dangerous due to the delicate nature of the surrounding anatomy. The composite model enabled the surgeon to very carefully navigate the anatomy with a focused resection and extreme care knowing the exact proximity of the L3 and $L 4$ nerve roots.

Conclusion: The patient had complete resection of this tumour, no neurological complication and full resolution of his symptoms due to careful, preoperative planning with the use of the composite 3D model.

Keywords: Composite, Pelvic tumour, Model, 3D, 3D-printing, Spine, Nerve
\end{abstract}

\section{Background}

3D printing has become increasingly utilized in the preoperative planning of clinical orthopaedics, orthopaedic trauma and other disciplines over the past decade [2]. Surgical treatment of bone tumours within the pelvis is challenging due to the complex 3D bone structure geometry, as well as the proximity of vital structures such as blood vessels, nerve roots, sciatic and femoral nerves and the bladder and/or rectum.

Reproducing the pre-operative plan as accurately as possible is crucial in pelvic tumour surgery, in order to

\footnotetext{
* Correspondence: andrewkanawati@yahoo.com.au

'Department of Orthopaedics, Westmead Hospital, Hawkesbury Road, Westmead, NSW 2145, Australia

${ }^{2}$ Harbour Spine Surgeons, 207 Pacific Highway, St Leonards, NSW 2065, Australia
}

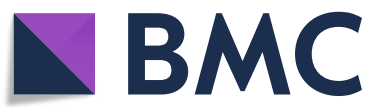

(C) The Author(s). 2021 Open Access This article is licensed under a Creative Commons Attribution 4.0 International License, which permits use, sharing, adaptation, distribution and reproduction in any medium or format, as long as you give appropriate credit to the original author(s) and the source, provide a link to the Creative Commons licence, and indicate if changes were made. The images or other third party material in this article are included in the article's Creative Commons licence, unless indicated otherwise in a credit line to the material. If material is not included in the article's Creative Commons licence and your intended use is not permitted by statutory regulation or exceeds the permitted use, you will need to obtain permission directly from the copyright holder. To view a copy of this licence, visit http://creativecommons.org/licenses/by/4.0/. The Creative Commons Public Domain Dedication waiver (http://creativecommons.org/publicdomain/zero/1.0/) applies to the data made available in this article, unless otherwise stated in a credit line to the data.

achieve negative surgical margins and thus decrease the likelihood of local recurrence, and reduce the risk of damage to vital structures $[1,12,15,18]$. However, resecting significantly more tissue than planned, out of concern for leaving a positive margin, can compromise patient function and/or successful reconstruction [12]. Thus, accuracy in executing the pre-operative plan is crucial for safe surgical margins, preserving maximum bone stock, reducing surgical morbidity by allowing approach planning and increase understanding of nearby vital structures.

We present a unique case where a composite bone and nerve model of the lower lumbar spine, pelvis and accompanying nerve roots were segmented using 3D Slicer version 4.10.2 (www.slicer.org), and 3D-printed using a Formlabs Form 2 (Formlabs Inc. Somerville, 


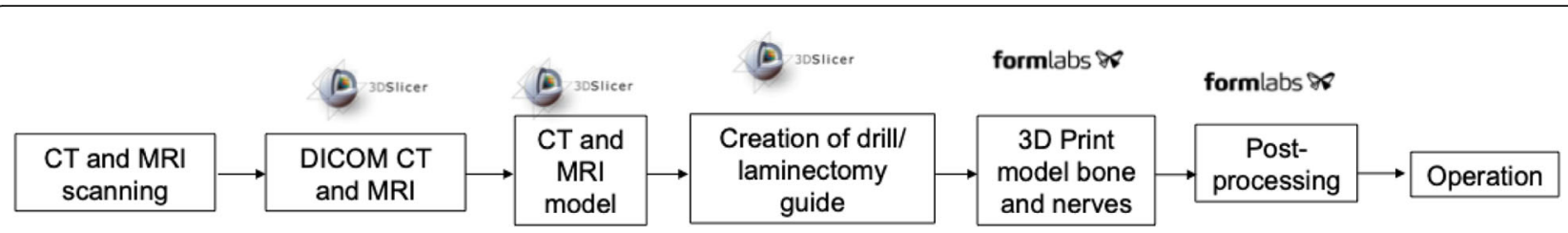

Fig. 1 Flow sheet demonstrating the creation and use of the composite model

MA) desktop 3D printer. The bony pelvis and spine were segmented using computed tomography (CT) data and printed in a solid material, whereas the nerve roots were segmented from magnetic resonance imaging (MRI) data, and printed in an elastic material (Fig. 1). The 3D-printed model created an accurate reconstruction of the pelvic tumour and traversing nerves for preoperative planning and allowed for efficient and safe surgery.

\section{Case presentation}

A 40 year-old male presented to our institution with a 20-year history of mild left-sided lower back and flank pain, secondary to an osteochondroma. His pain was activity related and was gradually increasing over 2 years. He occasionally complained of nocturnal symptoms.

Radiological imaging included serial CT and MRI of the lumbar spine (Fig. 2 and 3). The CT data was obtained using a GE Lightspeed VCT 64 slice CT Scanner with $0.625 \mathrm{~mm}$ slice thickness. The MRI data was obtained using a GE Healthcare $3 \mathrm{~T}$ Discovery MR750 scanner. The scan parameters for each modality are outlined in Tables 1 and 2. The most recent scans revealed a lesion originating from the posteromedial aspect of the left iliac crest lesion, adjacent to and surrounding the left L5 transverse process. It had a stable appearance since the patient's puberty and had no aggressive radiological features of chondrosarcoma. The MRI revealed the proximity of the L3, L4 and L5 nerve roots as they exited the intervertebral foraminae and before they passed into the psoas muscle.
The patient was conservatively managed however after 5 months he represented with progression of his symptoms reporting depressive symptoms and cessation of work because of the pain. He started to complain of pain and numbness in his thigh and knee, due to L3 and L4 radiculopathies. He responded well to selective nerve root injections, however his symptoms recurred and operative management was decided upon.

3D-printing of the pelvis CT and lumbar spine MRI were used for preoperative planning (Fig. 4). The CT digital imaging and communication in medicine (DICOM) was imported into 3D Slicer version 4.10.2. A region of interest was created around the left ilium, sacrum, L4 and L5 vertebrae, with a crop scale of 1.0 and isotropic spacing. The model was created by the 'grow from seeds' extension in the Segment Editor of 3D Slicer. Segmentation defects were corrected by modifying seeds and manual editing to ensure accuracy of the models. Closing (fill holes) and opening (remove extrusions) smoothing effects at a kernel size of $2 \mathrm{~mm}$ were used to obtain a final model. The model was made hollow with a shell thickness of $2 \mathrm{~mm}$, and was exported as a standard tessellation language (STL) file. The MRI DICOM was imported into 3D Slicer. The axial T2 weighted sequences were used to identify the nerve roots. The 'draw tube' extension in the Segment Editor of 3D Slicer was used to trace the L3, L4 and L5 nerve roots using a $2 \mathrm{~mm}$ radius. The nerve roots were combined into one model and exported as an STL file. The bone and nerve models were aligned to allow for closer assessment of the nerve roots relationship to the tumour. The L3 nerve was found to be traversing

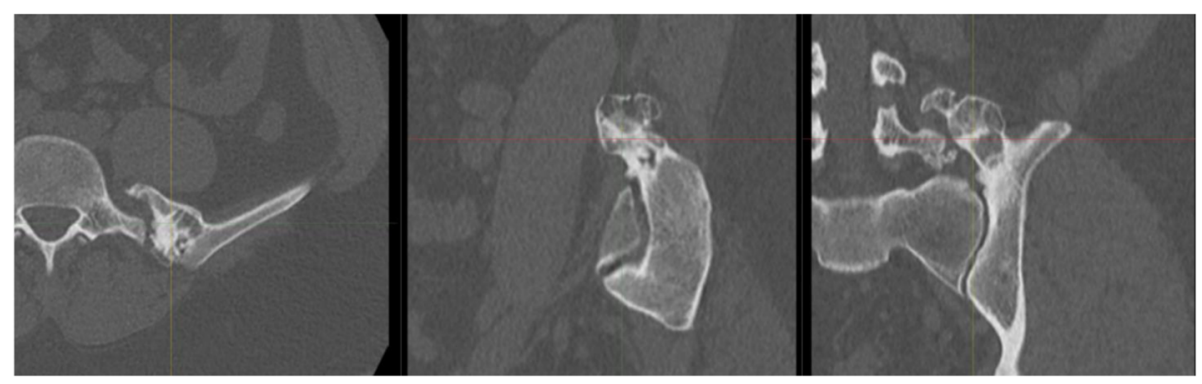

Fig. 2 CT slices demonstrating the bony architecture of the osteochondroma 


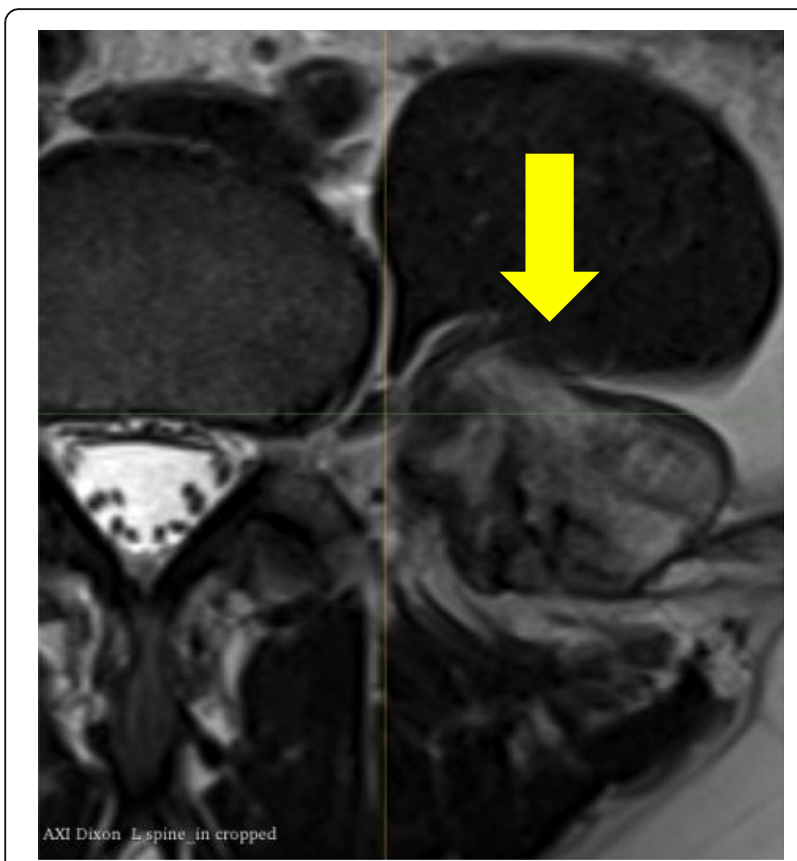

Fig. $3 \mathrm{MRI}$ demonstrating the $\mathrm{L} 3$ nerve root anterior to the osteochondroma (arrow)

directly anterior to the lesion and actually form a groove on the anterior and cranial surface (Figs. 4 and 5). The L4 nerve root was found to be traversing directly medial to the lesion.

The bone model STL file was imported into Formlabs Preform software (Version 3.0.2). Layer thickness was set to $0.1 \mathrm{~mm}$, supports were autogenerated and printed in Grey resin using a Formlabs Form 2 (Formlabs Inc.

Table $1 \mathrm{MRI}$ imaging parameters

\begin{tabular}{ll}
\hline Imaging options & Parameters \\
\hline Imaging Plane & Oblique \\
Imaging Mode & $3 \mathrm{D}$ \\
Pulse Sequence & Cube \\
Imaging Options & EDR, Fast, ZIP2, FR \\
Frequency Field of View & $300 \mathrm{~mm}$ \\
Phase Field of View & $60 \% \mathrm{or} 300 \mathrm{~mm}$ \\
Frequency Matrix & $384 \mathrm{~mm}$ \\
Phase Matrix & $384 \mathrm{~mm}$ \\
Slice Thickness & $0.8 \mathrm{~mm}$ \\
Slice Overlap & None \\
NEX & 2 \\
Flip Angle & $5 \mathrm{Degrees}$ \\
TR & $4800 \mathrm{~ms}$ \\
TE & $369 \mathrm{~ms}$ \\
Receive Bandwidth & $50 \mathrm{kHz}$ \\
Frequency Direction & $\mathrm{S} / \mathrm{l}$ \\
\hline
\end{tabular}

Table 2 CT imaging

\begin{tabular}{ll}
\hline Imaging options & Parameters \\
\hline Pitch & $0.984: 1$ \\
Table speed & $39.37 \mathrm{~mm} / \mathrm{ro}$ \\
Helical Full & $1.0 \mathrm{~s}$ \\
SFOV & Large Body \\
DFOV & 40 adjust as needed \\
Auto mA & ON \\
Smart mA & ON \\
Min mA & 200 \\
Max mA & 650 \\
Dose Reduction & $20 \%$ \\
Noise Index & 26 \\
ASIR & $40 \%$ \\
\hline
\end{tabular}

Somerville, MA) desktop 3D printer. The print time was $13 \mathrm{~h}$ and $15 \mathrm{~min}$, and print volume was $176 \mathrm{mls}$.

The nerve root model STL file was imported into Formlabs Preform software. Layer thickness was set to $0.1 \mathrm{~mm}$, supports were autogenerated and printed in Elastic 50A resin, using a Formlabs Form 2 desktop 3D printer. The print time was $3 \mathrm{~h}$ and $45 \mathrm{~min}$, and print volume was $18 \mathrm{mls}$. After printing, post-processing of the models included soaking in $99 \%$ isopropyl alcohol for $20 \mathrm{~min}$, and then UV curing for $30 \mathrm{~min}$ at 60-degrees Celsius in the Form Cure machine (Formlabs Inc. Somerville, MA). After removal of supports, the models were inspected to exclude printing failures or errors. No additional postprocessing was required.

The patient was positioned prone on a Jackson table after administration of a general anaesthetic. The tumour was approach via a posterior, longitudinal, paramedian incision (Wiltse approach). The posterior aspect of the tumour was dissected in a subperiosteal manner. A bone scalpel (Misonix, Farmingdale, NY) was used to make one osteotomy at the base of the lesion, adjacent to the superomedial aspect of the ilium. The lesion was removed en-bloc. Complete resection of the lesion was confirmed by comparing the resected lesion to the 3Dprinted model. Operative resection of the tumour took 58 mins, and was confirmed an osteochondroma on histology with negative surgical margins (Fig. 5). There were no intra- or postoperative complications, with complete resolution of symptoms at 2 weeks and 3 months postoperatively.

\section{Discussions and conclusion}

This case demonstrates a unique composite spine and pelvis model using a combination of 3D-printing of the exiting nerves from MRI scan data and the bony architecture from CT scan data. The use of elastic material to recreate neural soft tissue is a novel technique, and this 


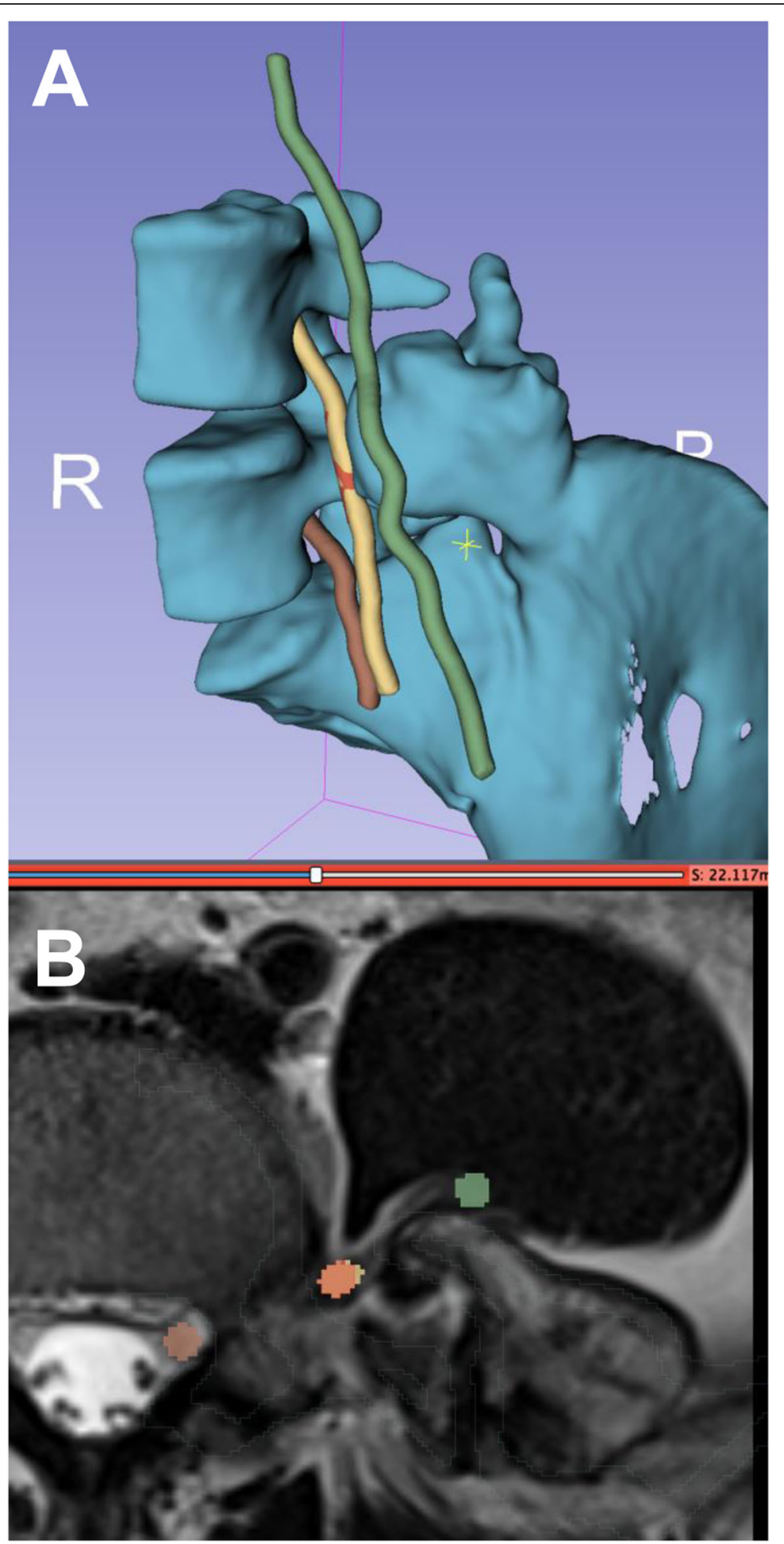

Fig. 4 A Composite segmentation model of the left ilium osteochondroma based on CT data, and L3-5 nerve roots based on MRI data (B)

elastic material can also be used to mimic other musculoskeletal soft tissue such as ligaments and tendons. Multiple pre-operative benefits included explaining the operative risk of iatrogenic nerve injury to the patient, but also provided a guide for intra-operative management. 


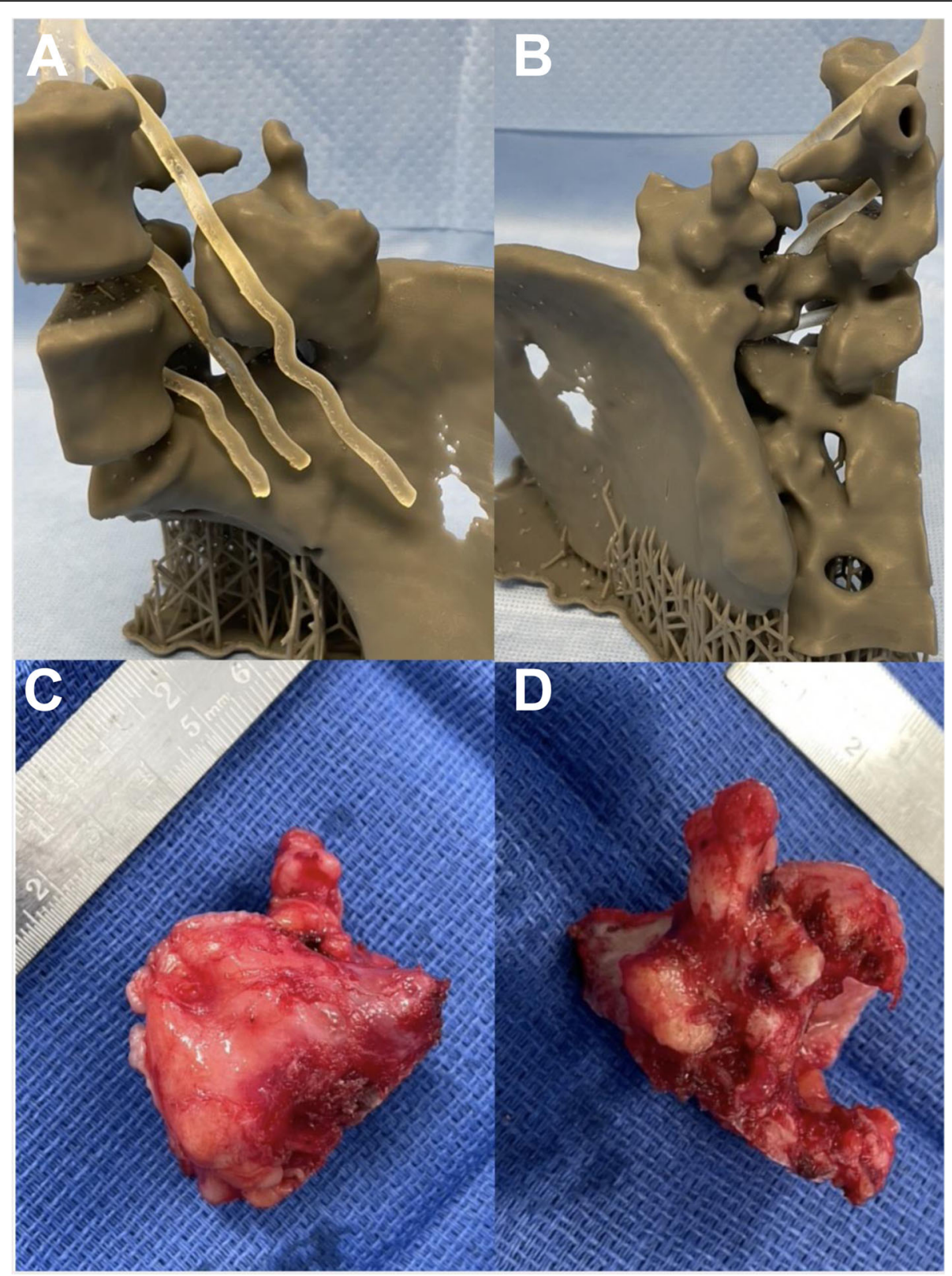

Fig. 5 3D-printed model combining the $C T$ and the MRI elements demonstrating the exact proximity of the nerve roots to the tumour. Anterior (A) and posterior (B) views. Corresponding anterior (C) and posterior (D) views of the excised osteochondroma

Several procedures for improving surgical accuracy have been described, such as computer-assisted surgical navigation, robot-assisted surgery and use of 3Dprinted patient-specific guides $[5,9,12,19,20]$. Several studies have validated CT and MRI in the creation of accurate 3D-printed models, as well as the use of 3D Slicer in the creation of musculoskeletal segmentation. Several of our previous reports have demonstrated the dimensional and volumetric accuracy of both CT and MRI data when compared to bone and 3D-printed models $[10,11]$. In a comparison of the 3D model and the cadaver pelvis, 3D printing resulted in accurate models suitable for preoperative workup [4]. 3D printing contributes to a better understanding of the surgical approach, reduction and fixation of fractures, especially in complex fractures such as acetabular fractures $[3,7$, 13, 14, 16]. Furthermore, more accurate reduction and shorter operation times can be achieved $[6,21]$. Additionally multiple cadaveric studies on pelvic tumours demonstrated more accurate osteotomies with 3D-printed patient-specific instruments compared to the standard manual technique $[8,17]$. 
Pelvic tumour surgery is inherently dangerous due to the delicate nature of the surrounding anatomy. The composite model enabled the surgeon to very carefully navigate the anatomy with a focused resection and extreme care knowing the exact proximity of the L3 and L4 nerve roots. The patient had complete resection of this tumour, no neurological complication and full resolution of his symptoms due to careful preoperative planning with the use of the composite 3D model.

\section{Acknowledgements \\ Not applicable.}

\section{Authors' contributions}

Olivia Fox was primarily responsible for the research, writing and publication of the case study. Andrew Kanawati was responsible for the care, CT and MRI 3D model construct and operative management of the patient. The author(s) read and approved the final manuscript.

\section{Funding}

No funding to declare.

\section{Availability of data and materials} Not applicable.

\section{Declarations}

\section{Ethics approval and consent to participate}

All procedures performed in studies involving human participants were in accordance with the ethical standards of the institutional and/or national research committee and with the 1964 Helsinki declaration and its later amendments or comparable ethical standards.

This article does not contain any studies with human participants or animals performed by any of the authors.

This article does not contain patient data.

\section{Competing interests}

The authors declare that they have no conflict of interest.

Received: 1 July 2021 Accepted: 5 September 2021

Published online: 25 September 2021

\section{References}

1. Bacci G, et al. Local Recurrence and Local Control of Non-Metastatic Osteosarcoma of the Extremities: A 27-Year Experience in a Single Institution. J Surg Oncol. 2007;96:118-23 Print.

2. Bagaria V, et al. Use of Rapid Prototyping and Three-Dimensional Reconstruction Modeling in the Management of Complex Fractures. Eur J Radiol. 2011:80.3:814-20 Print.

3. Borrelli J, et al. Assessment of Articular Fragment Displacement in Acetabular Fractures: A Comparison of Computerized Tomography and Plain Radiographs. J Orthop Trauma. 2002;16(7):449-56 Print.

4. Brouwers $L$, et al. Validation Study of 3D-Printed Anatomical Models using 2 PLA Printers for Preoperative Planning in Trauma Surgery, a Human Cadaver Study. Eur J Trauma Emerg Surg. 2019;45(6):1013-20 Print.

5. Cartiaux O, et al. Cartiaux O, Paul L, Docquier PL, Et Al. Computer-Assisted and Robot-Assisted Technologies to Improve Bone-Cutting Accuracy when Integrated with a Freehand Process using an Oscillating Saw. J Bone Joint Surg Am. 2010;92-A:2076-82 Print.

6. Chen XJ, et al. Modular Preoperative Planning Software for Computer-Aided Oral Implantology and the Application of a Novel Stereolithographic Template: A Pilot Study. Clin Implant Dent Relat Res. 2010;12:181-93 Print.

7. Chepelev $L$, et al. Radiological Society of North America (RSNA) 3D Printing Special Interest Group (SIG): Guidelines for Medical 3D Printing and Appropriateness for Clinical Scenarios. 3D Print Med. 2018:4:11 Print.

8. García-Sevilla M, et al. Patient-Specific Desktop 3D-Printed Guides for Pelvic Tumour Resection Surgery: A Precision Study on Cadavers. Int J Comput Assist Radiol Surg. 2021;16(3):397-406 Print.
9. Jeys L, et al. Can Computer Navigation-Assisted Surgery Reduce the Risk of an Intralesional Margin and Reduce the Rate of Local Recurrence in Patients with a Tumour of the Pelvis Or Sacrum? Bone Joint J. 2013;95-B:1417-24 Print.

10. Kanawati A, Fernandes RJR, Gee A, Urquhart J, Siddiqi F, Gurr K, et al. Geometric and Volumetric Relationship between Human Lumbar Vertebra and CT-Based Models. Arcad Radiol. 2020;S1076-6332.20:30332-9 Print.

11. Kanawati A, Rodrigues Fernandes RJ, Gee A, Urquhart J, Bailey C, Rasoulinejad P. Geometric and Volumetric Relationship between Human Lumbar Vertebrae and "Black-Bone" MRI-Based Models. Int J Med Robot. 2021;17(2):e2220 Print

12. Khan F, et al. Haptic Robot-Assisted Surgery Improves Accuracy of Wide Resection of Bone Tumors: A Pilot Study. Clin Orthop Relat Res. 2013;471: 851-9 Print.

13. Kim HN, Liu XN, Noh KC. Use of a Real-Size 3D-Printed Model as a Preoperative and Intraoperative Tool for Minimally Invasive Plating of Comminuted Midshaft Clavicle Fractures. J Orthop Surg Res. 2015;10(1):91 Print.

14. Mitsouras D, et al. Medical 3D Printing for the Radiologist. Radiographics. 2015;35(7):1965-88 Print.

15. Nagarajan $R$, et al. Limb Salvage and Amputation in Survivors of Pediatric Lower-Extremity Bone Tumors: What are the Long-Term Implications? J Clin Oncol. 2002;20:4493-501 Print.

16. Punyaratabandhu T, Liacouras PC, Pairojboriboon S. Using 3D Models in Orthopedic Oncology: Presenting Personalized Advantages in Surgical Planning and Intraoperative Outcomes. 3D Print Med. 2018:4:12 Print.

17. Sallent A, et al. How 3D Patient-Specific Instruments Improve Accuracy of Pelvic Bone Tumour Resection in a Cadaveric Study. Bone Joint Res. 2017; 6(10):577-83 Print

18. Wirbel RJ, Schulte M, Mutschler WE. Surgical Treatment of Pelvic Sarcomas: Oncologic and Functional Outcome. Clin Orthop Relat Res. 2001;390:190205 Print.

19. Wong KC, Kumta SM. Computer-Assisted Tumor Surgery in Malignant Bone Tumors. Clin Othop Relat Res. 2013;471:750-61 Print.

20. Wong KC, et al. Patient-Specific Instrument can Achieve Same Accuracy with Less Resection Time than Navigation Assistance in Periacetabular Pelvic Tumor Surgery: A Cadaveric Study. Int I Comput Assist Radiol Surg. 2016;11:307-16 Print.

21. Zeng C, et al. A Combination of Three-Dimensional Printing and ComputerAssisted Virtual Surgical Procedure for Preoperative Planning of Acetabular Fracture Reduction. Injury. 2016;47(10):2223-7 Print.

\section{Publisher's Note}

Springer Nature remains neutral with regard to jurisdictional claims in published maps and institutional affiliations.

Ready to submit your research? Choose BMC and benefit from:

- fast, convenient online submission

- thorough peer review by experienced researchers in your field

- rapid publication on acceptance

- support for research data, including large and complex data types

- gold Open Access which fosters wider collaboration and increased citations

- maximum visibility for your research: over $100 \mathrm{M}$ website views per year

At BMC, research is always in progress.

Learn more biomedcentral.com/submissions 